\title{
Improving MoWaS Application Backbone System for The Effectiveness of Responsive Behaviour in Facing Crime Threats and Emergency Situations
}

\author{
Arif Arizal ${ }^{*}$, Syariful Alim ${ }^{2}$ \\ 1,2Universitas Bhayangkara Surabaya \\ qariff@gmail.com
}

\begin{abstract}
MoWaS is a mobile-based supporting application aiming to improve the rapid response against crime crime and emergency situations. The evaluation of MoWaS version 1.0 has 3 flaws. First, it is unable to create a group. Second, the MoWaS version 1.0 application is able to detect the current location of the alert sender but there is no feature to display information about nearby MoWaS application users. Third, MoWaS application version 1.0 is also not integrated with the official service or government agency related to the types of occurring crime. The results of the design revision and analysis were made including the MoWaS system architecture design, the MoWaS system flow described in the form of flowchart, and the MoWaS system interface design. The results of the analysis and design of MoWaS backbone system can be used as the basis for improvement of MoWaS system development. Hence, it can be concluded that the MoWaS application version 2.0 has a better work system than the previous version.
\end{abstract}

Keywords: Alert, Warning System, Threats of Crime, Emergency Situation

\section{Introduction}

Nowadays, the crime rate is high having tendency to occur in home environment, urban or village area, office, and outdoor public space. Therefore, the tendency of having conditions for emergency situation is also increasingly high. This fact makes us more aware in facing all possible threats of crime and emergency situation [1][2][3][4][5][6].

In responding to those facts, it is necessary to develop an application that can facilitate public utilizing mobile technology to enhance the rapid response of handling crime threats and emergency situations [7][8][9]. MoWaS application is a mobile application serving to send and receive alert messages of crime threats and emergency situations in the surrounding area. In MoWaS application version 1.0, there are 10 types of crime features, such as thievery, robbery, sexual violence, murder, accidents, hurricanes, landslides, tsunami, floods, and other emergency situations. Other emergency-prone situations are used for other types of crime threats and emergency situations such as gambling, drunkenness, wild race, and another crime threats or emergency situations beside nine features previously mentioned. From the evaluation results in analysis and system designing stages, MoWaS application version 1.0 has the following deficiencies [10]:

1. Unavailability to create a group.

2. Inability to display other nearby MoWaS users at the location of the crime.

3. No integration with official service or agency related to the type of occurring crime.

Based on the background described earlier, it is necessary to carry out the analysis and re-design MoWaS application to overcome the deficiencies identified in version 1.0. By redesigning MoWaS application, the improvement of MoWaS application backbone system will also be carried out. Backbone system improvement in MoWaS version 2.0 application is expected to improve MoWaS application performance compared with the previous version. By improving performance of MoWaS applications version 2.0, potential crimes and possible emergency situations can be minimized or even avoided.

\section{Research Method}

The steps used to carry out analysis and system designing [11] of MoWaS version 2.0 are as following:

Arizal, A., \& Alim, S. (2017). Improving of MoWaS Application Backbone System for Effectiveness of Responsive Behaviour in Facing Crime Threats and Emergency Situations. Kinetik : Game Technology, Information System, Computer Network, Computing, Electronics, and Control, 2(4). doi:http://dx.doi.org/10.22219/kinetik.v2i4.250

Paper submitted on July 31, 2017; Revision on August 02, 2017; Received August 04, 2017 
1. Designing MoWaS version 2.0 system architecture.

2. Describing the workflow of MoWaS system version 2.0 using a flowchart form.

3. Designing MoWaS system interface version 2.0.

4. Evaluating the analysis results and system designing of MoWaS version 2.0.

\section{Results and Discussion}

Based on the initial analysis results, the general design of the MoWaS version 2.0 system architecture is as follows:

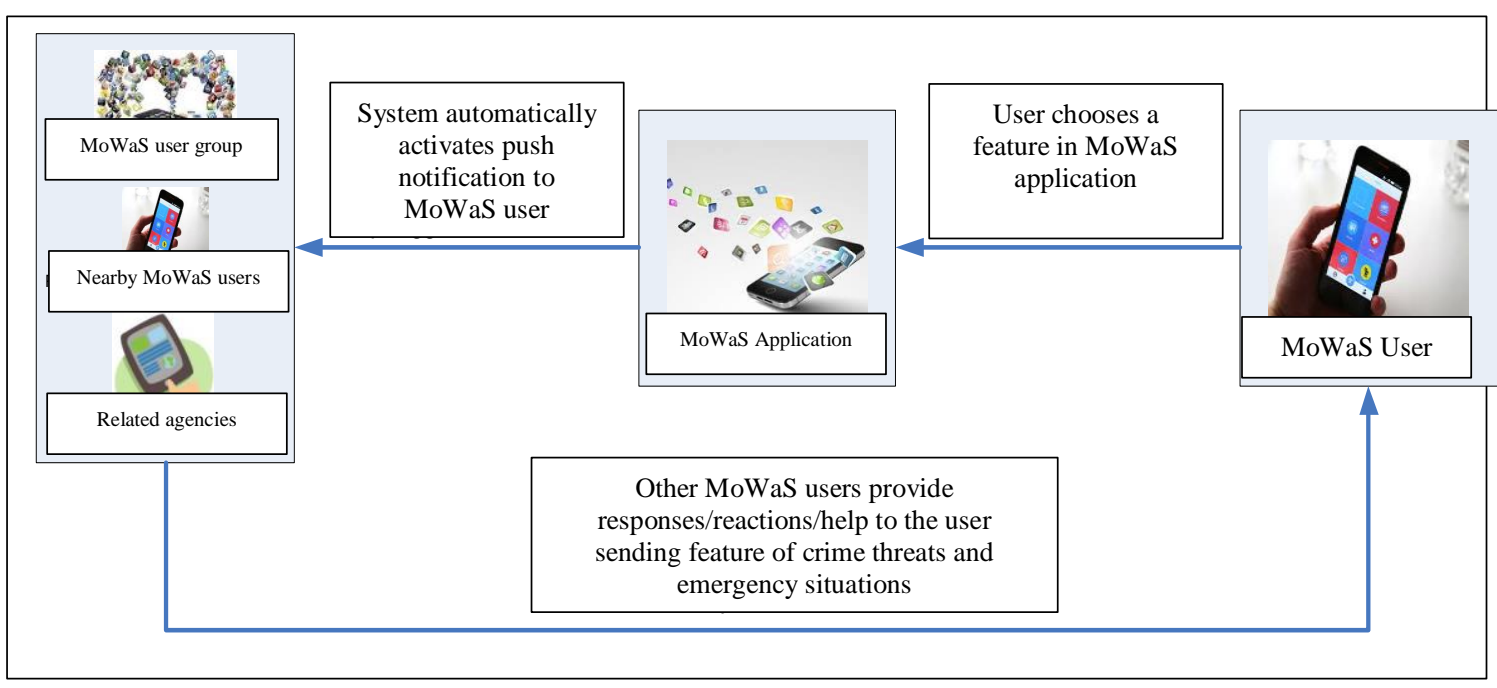

Figure 1. Architecture Design of MoWaS Version 2.0 Backbone System

Based on information illustrated in Figure 1, MoWaS version 2.0 application user who encounters a crime threat or emergency situation needs only to choose one of the crime threat features/icons found on the MoWaS application. Furthermore, MoWaS will automatically activate push-notification to:

1. All MoWaS application users being in the same group with the MoWaS user sending the alerts.

2. Other MoWaS application users who are in the vicinity of the threat location.

3. Official service or agency related to the type of occurring threat. For example, if a MoWaS user sends a fire alert then the Fire Department will receive the alert message.

The improvement on MoWaS version 2.0 backbone system overcomes the deficiencies found in the MoWaS application version 1.0. Thus, MoWaS application users who get the notification can give faster assistance to MoWaS users sending the alert. In detail, the workflow of MoWaS system version 2.0 is illustrated in the flowchart described in Figure 2. While the interface design of MoWaS application version 2.0 including the initial and the main form is presented in the Figure 3 to 9 .

The initial appearance of the MoWaS application version 2.0 when it is running is shown in the Figure 3. Moreover, the welcome screen designing is displayed in a splash screen. MoWaS version 2.0 also adds a feature for creating a group. This feature is added based on the evaluation results in the system designing of the previous version of MoWaS. By utilizing this feature, MoWaS version 2.0 users can create groups according to user needs.

The group feature is highly useful as the basis filter in sending the alert to other MoWaS users. Consecutively, sent alerts will be adapted to the user's setting, whether the alerts sent will be forwarded to all MoWaS users randomly or only to certain users who are in one group with the sender who sends the alert. If the user wants to see which users are registered in a particular group, he can simply select one of the available group names. The example of group member list can be examined in Figure 6.

Figure 6 shows a list of other MoWaS users populating one group. If a MoWaS user wants to add or remove other MoWaS users in a group, he can simply press one of the available buttons. 
Workflow of Mobile Warning System (MoWaS) version 2.0

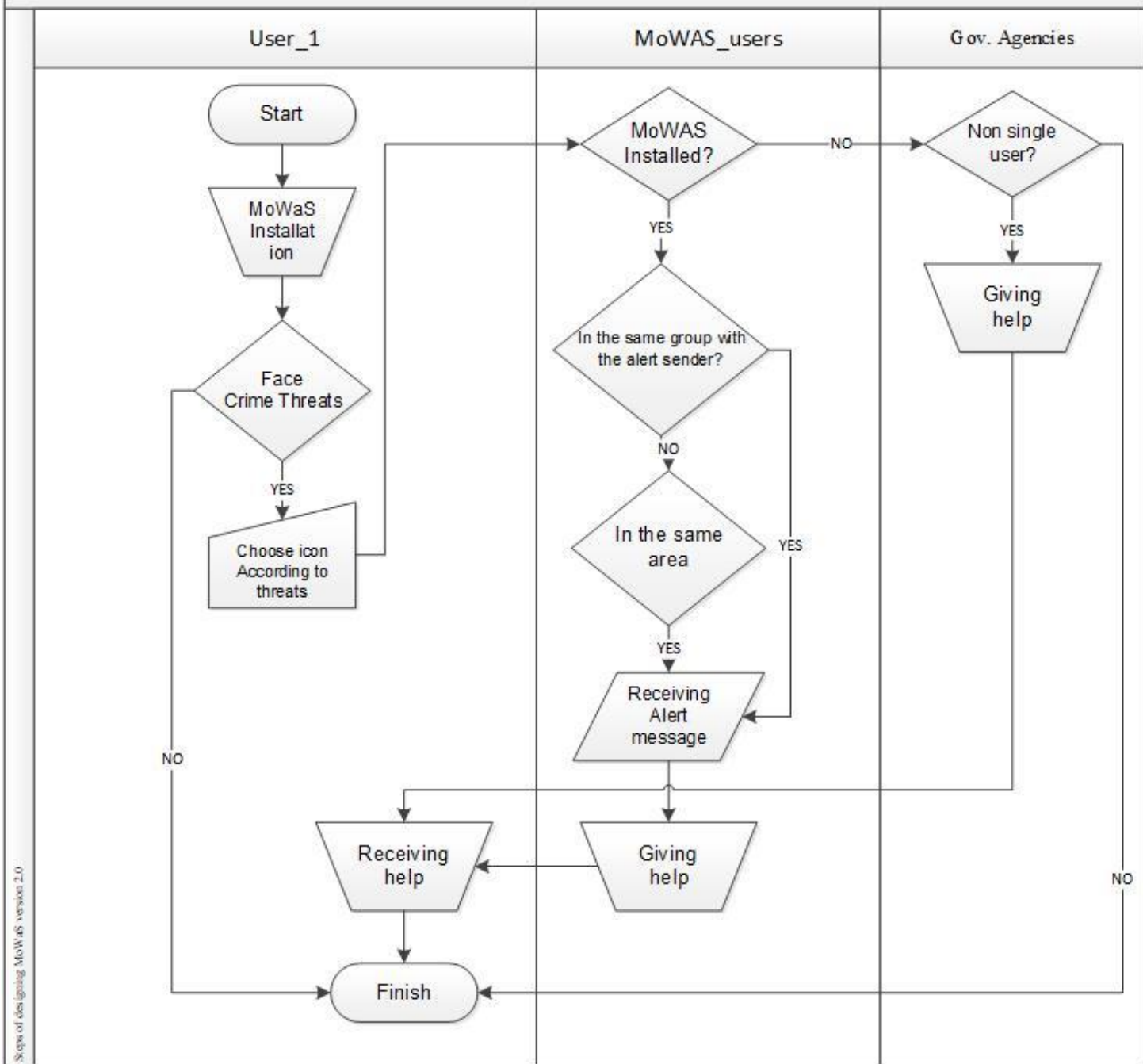

Figure 2. Workflow of MoWaS System Version 2.0

Welcome

Early Warning System

to Crime Threats and

Emergency Situations version 2.0

Figure 3. Welcome Screen 


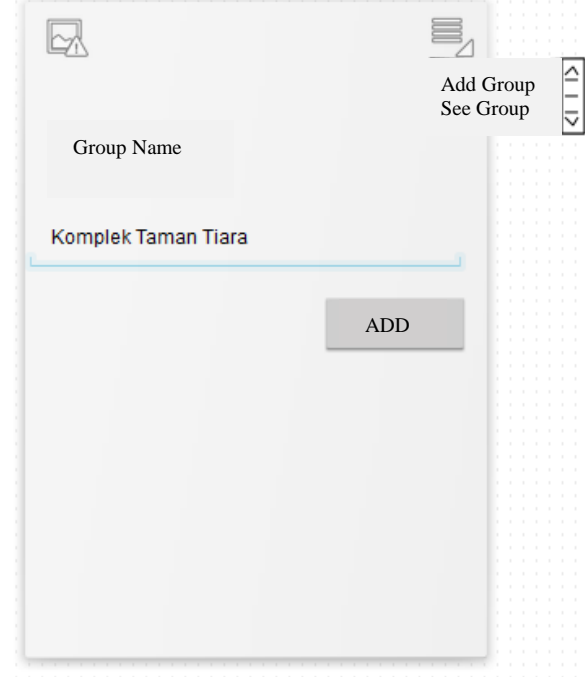

Figure 4. Feature to Create a Group

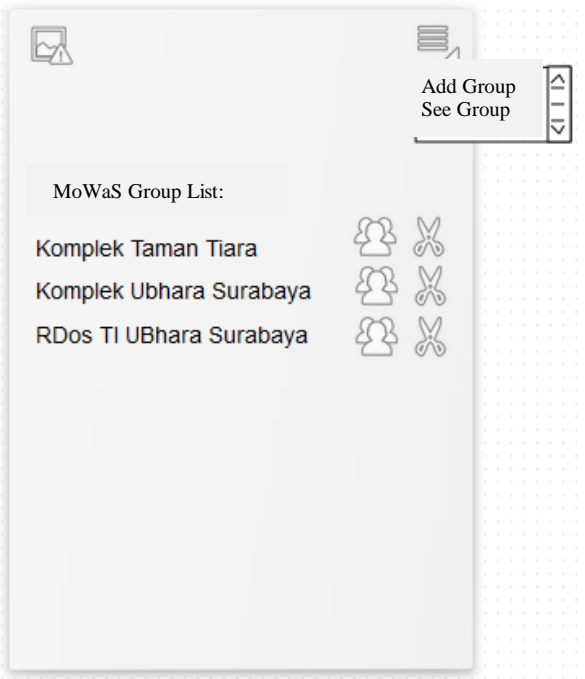

Figure 5. List of Groups Created by Users

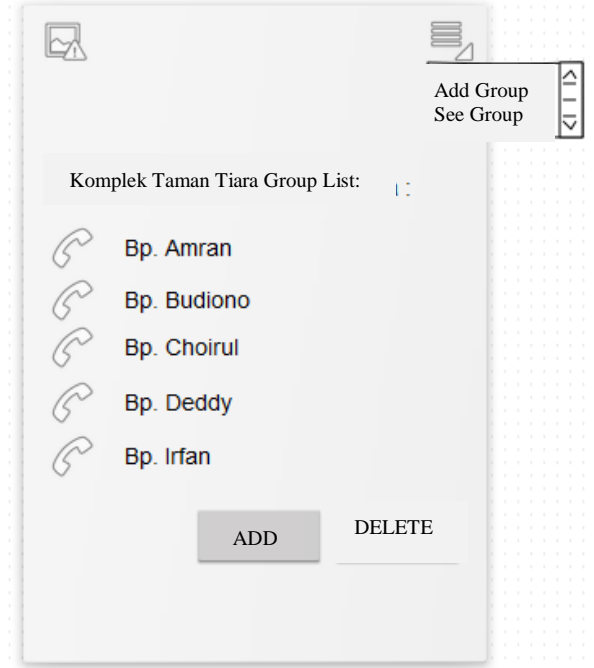

Figure 6. Example of A Group Member List Created by Users 


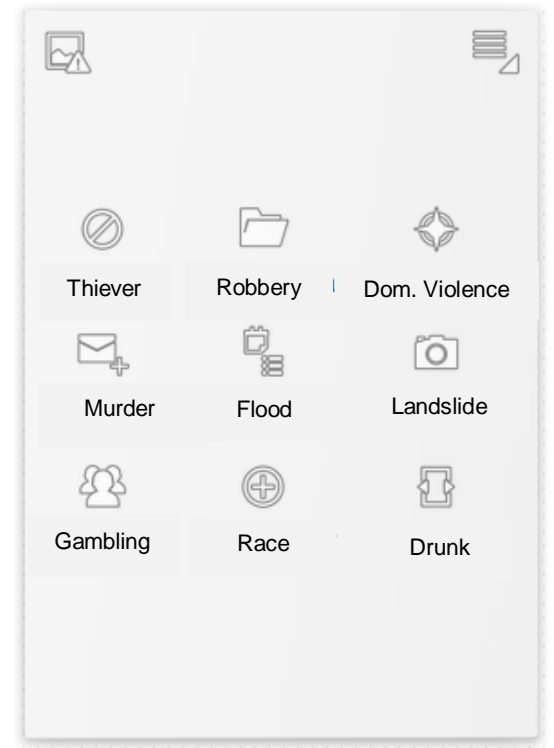

Figure 7. The Design of the Main Form

Figure 7 illustrates the design of the main form in MoWaS version 2.0, conveying similar design to the previous version. Choices of crime threats or emergency situations are represented by mini icons. If the MoWaS user encounters a crime or other emergency situation, the MoWaS user only needs to click one of the available mini icons. For example, a user selected the "Gambling" mini icon then the user's choice will be forwarded by the server to other MoWaS users.

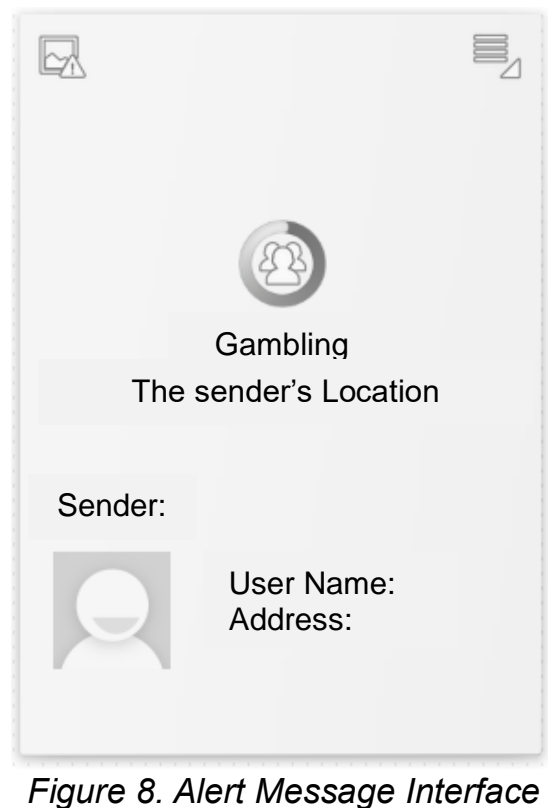

Figure 8 shows message interface for other MoWaS users. The system will automatically send alerts to MoWaS users in the same group with the sender of alerts and to other nearby MoWaS users. The sending alerts use notification form displaying the type and the location of occurring crime threat. The system will also show the user's personal information who send the alert.

In addition, the system will also automatically send the alerts to official service or government agency related with the specific threat of crime. For example, for alert type "Gambling" then the Police will also receive this alert.

Each design of MoWaS system version 2.0 will be evaluated first. The results of the evaluation are as follows: 
1. MoWaS application version 2.0 provides feature that can create a group. Moreover, based on feedbacks from users, the capability to limit the alert receivers to selected users has been established, providing faster reinforcement arrival.

2. MoWaS version 2.0 also is capable of detecting the location of other nearby MoWaS users located at the place of event, providing faster reinforcement arrival.

3. MoWaS version 2.0 can be a part of integrated security system related to official services or government agencies. Therefore, the information displayed in the push notification interface is not only accepted by fellow MoWaS users, but it is also accepted by the official government services or agencies.

The output of MoWaS version 2.0 is expected to be a preliminary study for further research having similar area mapping to the crime threats based on the types of crime and other emergency situations.

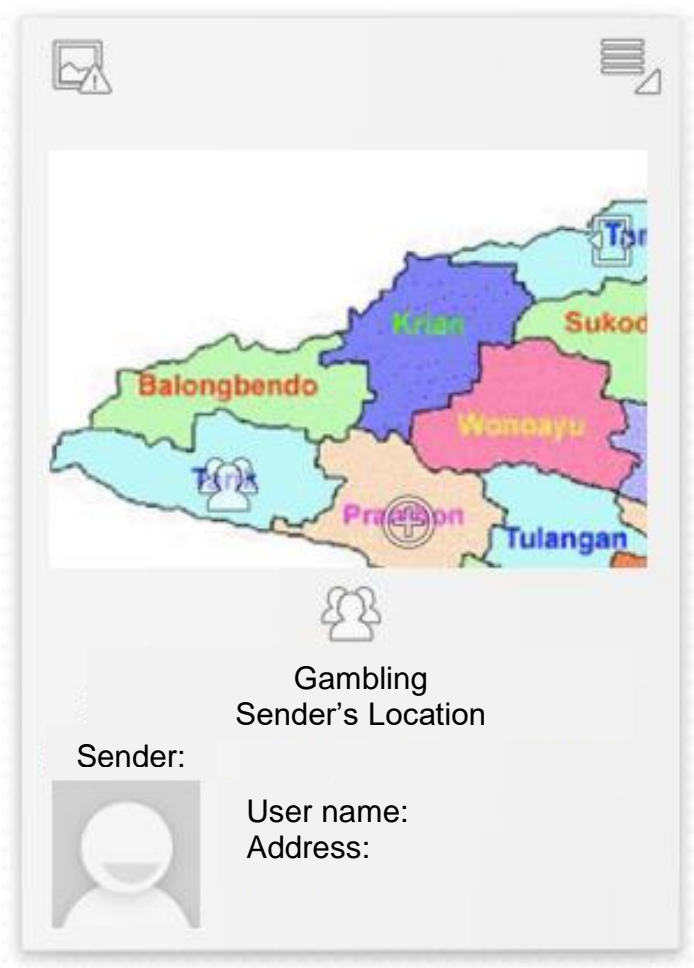

Figure 9. The Interface of Alert Message in the Official Service or Government Agency

\section{Conclusion}

The analysis and design of MoWaS system version 2.0 use structured analysis and design approach. These analysis and redesign of MoWaS aims to fix the backbone system of the previous version. It is carried out based on the evaluation results of MoWaS system design version 1.0.

MoWaS system design version 2.0 is presented in the form of system architecture, flowchart, and MoWaS interface design. The results of analysis and design of MoWaS system design can overcome the recognized drawbacks found in version 1.0; hence, it can provide better compatibility to user requirements. The output of MoWaS version 2.0 can also be a preliminary study for further research designing similar area mapping approaches related to handling crime threats based on the types of crime and other emergency situations.

\subsection{Acknowledgement}

This study is greatly in debt to DRPM Director General of Ministry of Research, Technology and Higher Education (Kemenristek Dikti) providing financial support through Beginner Lecturer research scheme in 2017. Thus, the research implementation of "Mobile Application Development of Warning System to Improve Response Behaviour Against Crime Threat and Emergency Situation" can be carried out. 
References

[1] D. P. Rara, "The Determinant Analysys of Fear of Crime Triggers on Thievery Cases on Housewives," Vol. 5, No. 1. Criminology Department, Faculty of Social and Political Science, 2009.

[2] S. Harseno, "Development of SIG and Early Landslide Warning in Yogyakarta Utilizing Web Service and API Google Maps based on Android," Universitas Gadjah Mada, 2015.

[3] F. R. Kodong, "Application of Volcano Status Monitoring Using Telemetry Temperature," in National Seminar on Informatics (SEMNASIF), Vol. 1, No. 5, 2009.

[4] M. T. Nurzaki and W. Wijanarto, "Automatic Routing based on Genetic Algorithm for Rapid Response," Information Technology Journal, Vol. 14, No. 2, 2015.

[5] K. S. Pribadi, D. Ayu Krishna Yuliawati, K. Kunci, and A. Disaster Management from ITB Mitigation Center, "Education on Earthquake Rapid Resonse to Improve Student Safety (Case Study in Cirateun and Padasuka 2 Elementary School in Bandung Regency)," Universitas Syiah Kuala, Aceh, 2008.

[6] A. Affandi, D. Riyanto, I. Pratomo, and G. Kusrahardjo, "Design and Implementation of Fast Response System Monitoring Server Using Simple Network Management Protocol (SNMP)," in International Seminar on Intelligent Technology and Its Applications (ISITIA), 2015.

[7] R. B. Reeley, "Mobile Detection and Alert System," US6166627 A, 2000.

[8] Michael W. Bulmer, "Alert System," US7126454 B2, 22-Nov-2006.

[9] H Lemelson Jerome and D. P. Robert, "Personal Emergency, Safety Warning System and Method," US6028514 A, 2000.

[10] A. Arizal and S. Alim, "Analysys and Design of Mobile Warning System (MoWaS) to Improve Rapid Response to Crime Threats and Emergecy Situations," in National Seminar on Information Technology (SNATIF), Pp. 883-887, 2017.

[11] H. M Jogiyanto, "Analysys and Design of Information System: Structured Approach, Theory, and Business Application," Third Edition, Yogyakarta: Andi Offset, 2005. 
